\title{
Competence-Enhancing Interventions and Organisational Performance: A Theoretical Review
}

\author{
Idowu Owoeye ${ }^{1}$, Stephen Makau Muathe ${ }^{2}$ \\ ${ }^{1}$ Department of Human Resource Management, School of Business, Kenyatta University, Nairobi, Kenya \\ ${ }^{2}$ Department of Business Administration, School of Business, Kenyatta University, Nairobi, Kenya
}

Email address:

iddupe@yahoo.com (I. Owoeye), muathesm@yahoo.com (S. M. Muathe)

\section{To cite this article:}

Idowu Owoeye, Stephen Makau Muathe. Competence-Enhancing Interventions and Organisational Performance: A Theoretical Review. Journal of Human Resource Management. Vol. 6, No. 2, 2018, pp. 67-77. doi: 10.11648/j.jhrm.20180602.14

Received: July 2, 2018; Accepted: July 30, 2018; Published: August 23, 2018

\begin{abstract}
The basic assumption in Human resource management is that people remain significant to the attainment of performance that an organisation desires. To achieve performance, it is requisite to invest in the competencies of individuals working in the organisation. The investment entails mobilising the necessary interventions to enhance the competencies of organisational workforce towards achieving organisational performance. While efforts have been concentrated on the studies of interventions for enhancing the skill and knowledge which constitute an aspect of individual competency, the other areas of competency as described by competence iceberg model has been largely unattended to. Therefore, this study presents the review of theoretical and empirical literature of the various interventions for enhancing the competencies of employees and organisational performance. Based on the reviewed theoretical and empirical literature, the study proposes a conceptual model that advances knowledge on what constitutes employee's competencies and organisational performance, and their relationship, especially in the field of Human resource management.
\end{abstract}

Keywords: Competence-Enhancing Interventions, Competence Iceberg Model, Organisational Performance

\section{Introduction}

In today's competitive global and dynamic market environment, sustainable competitive advantage remains what a firm needs to outwit its competitors [1]. Organisations are intensifying efforts to ensure that competitive advantage is achieved by building capacities that are valuable, rare, inimitable, and difficult to be substituted. As remarked in literature, creating unique goods and services, providing incessant capital flow and developing modern technologies are unavoidable conditions determining the market entry of a firm today [1], however, technologies and capital have been considered as imitable, not rare, and have become commodities available to be acquired at the market prices [2], therefore, the search for competitive advantage beckons on developing organisational capacities in terms of enhancing competencies of workforce. Many organisations have come to realise that the competences of workforce remain a key factor and important capability for obtaining competitive advantage [3]. The organisational workforce constitutes human capital element that represents people in the organization; the combined intelligence, skills and expertise that offer the organization its unique character. The human elements are regarded as the valuable assets worthy of investment to deliver the success that an organisation desires [4]. In order to obtain and retain human capital elements for achieving competitive advantage and performance, a pivotal attention needs to be accentuated to the enhancement of competences of people working in the organisation.

Competence is a concept that is sometimes synonymously used as the word 'skill', however, scholars have provided further and elaborate explanation of the concept. Competence refers to as underlying attributes of a person in terms of motive, trait, skill, aspect of one's image, social role, or a body of knowledge which he or she offers for use [5]. Competence can also be explained as a bundle of affiliated skills, knowledge and attitude that has effect on significant part of one's job, a correlation with performance on the job, is measurable against acceptable standards, and that can be subject to improvement through training and development [6]. Competence, in a broader view, refers to as a 
combination of implied, individual and collective knowledge, capacity behaviour and skills that result in effectiveness, efficiency and superior performance [7]. Competence, therefore, is a true applied knowledge and utilised capacity of an individual or an organisation.

The distinctive characteristic of HRM rests on the assumption that performance is attained through human elements in an organisation [8], and the key to attain sustainable advantage hinges on the ability and knowledge utilisation of workforce [1]. Since people are indispensable to the success of an entity, it is imperative for organisation to invest in building the competencies of its workforce for the purpose of achieving sustainable advantage. Many organisations claimed nowadays to be accommodating soft HRM practices and policies but the fact remains that they have these practices and policies notionally, or may be in a dysfunctional and demoralised condition [9]. Even in organisations that claimed to be practicing good HRM practices, the perception of fairness of these practices will determine important employee attitudinal and behavioural outcomes. It is assumed that when an organisation invests in interventions or practices aimed at enhancing the competencies of its workforce, the proximal effect will be positive attitudinal outcomes which, in turn, lead to organisational performance.

In most Human resource management literature, major attention has been focussed on the link between HRM practices and performance at the expense of HRM interventions that can be used to enhance competencies of employees so as to drive organisational performance. Therefore, this study seeks to advance a research agenda on competence-enhancing interventions and performance relationship via a review of theories and extant literature in the field of Human Resource Management.

\subsection{Statement of the Problem}

The key assumption in Human resource management rests on the premise that performance can be achieved via people in the organisation [8]. This assumption has been the major focus of studies in human resource management literature, and among scholars and researchers. In an attempt to comprehend the link between human resource and organisational performance, empirical studies covering human resource practices have been investigated. Human resource practices have been elucidated as those activities that are performance-enhancing in nature, and also bundle of activities to improve performance outcomes [10, 11]. HRM practices can be explained as bundles or systems of human resource policies and practices that influence firm performance [12], and set of employment practices that are aimed at gaining the commitment of employees [13]. A growing body of studies in Human resource management pointed to a common direction that these practices have the potentials to enhance the skills, knowledge and experience of organisational workforce towards attaining the predetermined organisational goals. If these practices are put in place to enhance skills, knowledge and experience, therefore, the focus then is meant to enhance a single aspect of employees' competencies, and this has accounted for the erroneous definition of competence as the skills or knowledge that employees possess to execute the jobs they are engaged to do in the organisation.

A competency is defined as underlying attributes of a person that could be trait, skill, aspect of one's image, social role, or a body of knowledge that he or she makes use of [7]. In the similar vein, competence refers to as a bundle of skills, knowledge, and attributes that affects the job a person does [1]. The competency iceberg model is an important model for explaining what constitutes competencies of individuals in an organisation. The iceberg competency model presents human structure of competency in form of iceberg. This model divides competence into two parts: the upside water surface competence and the below water surface competence. The components comprising the upside water surface competence include skills and knowledge (know-how). The competences at the upside water surface can be observed and measured and they are instrumental to the performance of job in an organisation. The below water surface components of the iceberg competency model include value, self-image, character/personality, self-force/social motivation and amongst others. These components, as specified in the Iceberg model, are the hidden and the most neglected competencies possessed by individuals in an organisation. The components below the water surface of the iceberg competency model are the distinctive characteristics of individuals or employees within the organisations that will lead to superior performance.

The Iceberg competency model constitutes a context for understanding individual competencies within the organisations. Drawing from the iceberg model and definitions put forth by scholars, competence means more than the skills and the knowledge that people possess in in organisation. It encompasses unseen characteristics or attributes that drive people to attain superior organisational performance. Researchers and scholars have therefore only addressed the observed and measured aspect of individual competencies at the expense of other distinguishing attributes that lead to superior performance. Asides the limited explanation of the term competence, researchers and scholars have concentrated major efforts on macro level analysis with the aim of finding the link between interventions or practices for enhancing employees' competencies and organisational performance [14-16]. Competence-enhancing interventions are largely meant to improve the efficiency and effectiveness of an organisational workforce so as to obtain competitive advantage which will, in turn, lead to performance. It is therefore significant to measure the effectiveness of these interventions using people who are direct and potential beneficiaries as a unit of analysis. The understanding of competence-enhancing interventions at the level of organisation workforce will enable researchers and scholars to find out whether organisations are having these practices notionally or in a demoralised and dysfunctional condition.

In Human resource management literature, lack of 
appropriate and non-use of theories has limited the understanding of employment practices that can enhance organisational performance. There is, therefore, a need to develop and continue use of theories to foster the understanding of the link between HRM practices and organisational performance [8]. Apart from the dearth of theories for linking interventions for enhancing employees' competencies and performance, efforts on the part of scholars have not been really channelled to investigate the perceived overall fairness of these interventions by people working in the organisation. Therefore, the justice perception of these interventions becomes an issue that needs to be examined so as to understand competence-enhancing interventions and performance link.

\subsection{Objectives of the Study}

This study seeks to address three main objectives: (i) to review the theoretical and empirical literature on the constructs of competence-enhancing interventions and organisational performance, (ii) to identify the emerging theoretical and empirical gaps that form the basis for future research, and, (iii) to finally propose a theoretical model for responding to the identified gaps.

\section{Review of Relevant Theories}

In order to respond to the objectives of this study, there is need to review some theories that have been mobilised by scholars and researchers in Human resource management literature. This review will help in mobilising appropriate theories to model the constructs of competence-enhancing interventions and performance link. Some of the theories underpinning the HRM practices and performance link to be examined in this study include: Resource-Based View (RBV), AMO theory, Social Exchange theory, Affective Event theory, and Contingency theory.

\subsection{Resource-Based View Theory}

Resource-Based View (RBV) is an approach that emerged in 1980 to 1990 which is traceable to the major published works such as the Resource-Based view of the firm by Wernerfelt, the Core competency of the Corporation by Prahalad and Hamel, and Firm Resources and Sustained Competitive Advantage by Barney. Resource-Based View is an approach that explains that sustainable competitive advantage can be obtained provided a firm engages in development of resources and capacities that remain valuable, rare, inimitable, and not substitutable. The proponents of this view argue that organisations should analyse their internal environment to find out the sources of competitive advantage instead of expending much time in $\mathrm{x}$ raying competitive environmental forces. This theory was formalised by Barney in 1991. Organisational resources can be classified into three major areas: physical capital resources, human capital resources, and organisational capital resources. Physical capital resources available for firm include physical technology, plant and equipment, geographic location, and raw materials accessibility [17]. The human capital resources include competences of individual managers and workers in a firm. The organisational capital resources include a firm's formal reporting structure, its formal and informal management systems, and, as well as informal relation among groups within a firm, between a firm and those in its environment.

These are the resources that enable a firm to design and execute a value-creating strategy. Sustainable competitive advantage is achieved when a firm implements a strategy not simultaneously being implemented by current or potential competitors [17]. The argument in this theory is that an organisation would eliminate uncertainties and remain competitive advantaged in the external environment if it is able to build internal capacities and potentials which are valuable, rare, inimitable, and have no substitute. Although, Barney argues that not all the resources possessed by organisation will help in conceiving and implementing strategy for occasioning efficiency and effectiveness, the resources that are considered valuable, rare, inimitable, and not substitutable will help an organisation to obtain sustained competitive advantage. Such resources, according to Barney, will help organisations to design and apply strategy that will enhance efficiency and effectiveness better than the competitors in the market.

In Human resource management literature, the resourcebased view theory has been extensively mobilised to explain the nexus between HRM practices and organisational performance. In the review of Human resource management literature, Resource-Based View (RBV) remains one of the theories that have been extensively used to ground the HRM practices and organisational outcomes link [2]. The usefulness of this theory to HRM is that it provides a ground for understanding the importance of people as a relevant resource to the success of an organisation. Since people remain an invaluable asset and important resource that embraces the features of rareness, inimitability, and nonsubstitutability, an organisation can, therefore, invest in competences and capacities enhancement of its workforce so as to obtain sustainable competitive advantage. ResourceBased View theory is relevant to this study because of its connectivity with HRM interventions and performance relationship. The mobilisation of RBV theory in this study will be to model the proposition that states performance can be obtained if an organisation invests in interventions meant to enhance the competencies of its workforce.

\subsection{AMO Theory}

Another important theory that has been extensively mobilised for conceptualising interventions for enhancing human resource competencies is AMO framework. According to AMO framework, effective discretionary effort is a function of employees' abilities, motivation and opportunity to participate. Employees will perform well when they have the capacity to do so (i.e. abilities), motivation to do so (i.e. incentives), and, opportunities to do so (i.e. opportunity to 
participate). The conceptualisation of high performance work systems using AMO framework provides a theoretical framework or ground for other Human resource management researchers to operationalise the practices that will enhance competencies of people working in an organisation. According to [18], human resource practices influence performance through their impact on employees AMO to participate. AMO framework, since it was developed to conceptualise high performance work practices by [18], has become a veritable theoretical framework for many HRM scholars to ground the link between human resource practices and organisational effectiveness. The 'people performance model' is a product of AMO framework that explains employee AMO to participate in the organisation will occasion proximal attitudinal outcomes such as commitment, motivation, and job satisfaction, which in turn, leads to discretionary behaviour that will generate performance outcomes [19]. AMO framework has been mobilised to decompose HRM interventions into three dimensional areas such as ability, motivation and opportunityenhancing practices, and evidence from empirical has shown positive correlation of these dimensions with both employees and organisational outcomes performance [20-23].

In this study, the AMO theory will be mobilised to decompose the composite construct of competenceenhancing interventions into ability, motivation, and opportunity-enhancing interventions, and construct of organisational performance and the relationship between them. Drawing from AMO theory, it is assumed that investment in interventions for enhancing the competencies of employees in the organisation will generate effective discretionary efforts that will pave way for both positive employees and organisational outcomes.

\subsection{Affective Event Theory}

The Affective Event Theory (AET), was developed by Weiss and Cropanzano in 1996. The theory was designed to explain the causes and results of affective of experiences at work. According to this theory, workers' feelings and emotions at workplace largely determine work-related outcomes. The theory suggests that certain events in workplace are as a result of work environment features. These events, according to Weiss and Cropanzano, stimulate different affective reactions, which, in turn, influence employees' attitudes and behaviours.

The Affective Event Theory, though does not state the work environment features or work events that stimulate different affective reactions, literature has provided some clues that human resource practices have a positive relationship link with affective reaction [24]. HRM practices such as achievement, recognition, advance/growth, and feedback are the most common events to which employees attribute positive affective reactions [25]. In the study of Wegge, et al., (2006), employee perception of organisational practices and policies such as opportunity for participation, supervisory support, and concern for welfare, are positively related to positive affective reactions [26]. High performance human resource practices, as a bundle of interventions, are events that are used to communicate important organisational values, signal to employees that they are pivotal members whose relationship is long-term valued, and have a propensity to advance positive affective responses [24]. Human resource interventions may likely be accounted as events within the work environments that may create a discretionary effort or behaviours which, in turn, lead to organisational performance.

Affective Event Theory is relevant to this study because competence-enhancing interventions will be modelled as events that will influence positive experience, which in turn, occasion positive attitudinal outcomes in the organisation. It is assumed that if employees perceived that the organisation is interested in investment to improve their competences, they may likely be motivated and assumed positive behaviour and this may lead to organisational performance.

\subsection{Social Exchange Theory}

The Social exchange theory has a root traced to both sociology and social psychology. The key contributors to this theory include the likes of George Homans, John Thibaut, Harold Kelley, and Peter Blau (1958-1974). The social exchange theory was more formalised by scholar like Emerson in 1976. Social exchange theory advances understanding of employer-employee relationship that social behaviour emanates from an exchange process. The motive of this exchange is the maximisation of benefits and minimisation of costs. According to this theory, people compare the potential benefits and risks of social relationships. When the risks override the rewards, people result to termination or abandonment of that relationship. According to exchange theory, as people relate over time, they experience the need to reciprocate the gestures of the other persons. This is called the norm of reciprocity.

Social exchange theory can be used to explain important relationship that exists between people and their organisations. If employees perceive that their organisation considers them as a valuable asset, they may likely reciprocate this as a gesture towards assuming positive behaviour within the organisation. In this study, the social exchange theory will be mobilised to model the constructs of competence-enhancing interventions and organisational performance and their relationship.

\subsection{Contingency Theory}

The contingency theory scholars argue that better organisational performance will be achieved if there is a fit between HRM strategy and business strategy [27-28], 7). Scholars using contingency approach to model Human resource practices and performance fit have continued to argue that Human resource strategy would be more productive only when rightly combined with a specific organisational and environmental context [29]. Using contingency theory, organisations that closely coordinate their business strategies and Human resource management strategies achieve better performance outcomes in 
comparison to organisations that do not [30]. Contingency theory has a connection with performance and therefore becomes relevant in this study. It is assumed that bundles of complementary HRM interventions and organisational strategies fit will enhance employee competences which, in turn, occasion organisational performance.

\section{Review of Literature}

This section covers the review of the concept of competence as it relates to individuals working in organisation and some scholarly works on the constructs of competence-enhancing interventions and performance link. This review becomes significant for it addresses the constructs of this study and beams a light on the objectives that this paper seeks to achieve.

\subsection{Competence as a Concept}

The term competence is a concept that is being synonymously used as 'skill' in a confusing way. But literature has provided some definitions that delineate the term from the word 'skill'. In Human resource management literature, the major focus is on individual competencies and how these competencies can be improved so as to attain organisational performance. According to McClelland (1973), competence refers to as a trait that characterises a person which is related to superior performance, and exhibition of particular talents and practices, and also application of knowledge required to perform a job [31]. In the similar vein, competencies is explained as underlying attributes of a person that could be trait, skill, aspect of one's image, social role, or a body of knowledge that he or she makes use of [7]. Furthermore, competence can be described as a bundle of skills, knowledge, and attributes that affects the job a person does [1]. It (competence) is seen as a concept that has a correlation with performance of the job, can be measured against a particular standard, and, can be improved upon [1]. Competencies are also viewed from the individual perspective in an organisation and defined as a related set of attributes used or needed in executing a job [32].

The common ground in these definitions is that competencies are needed for improving and performing jobs by employees or individuals within the organisation. This is the perspective that Human resource management is focussing in an organisation. Human resource management is focussing on individual competencies and how these competencies can be improved so as to obtain organisational performance. Competencies have also been seen as the attributes of an organisation as a whole. In strategic management, competence encompasses all organisational capabilities for achieving competitive advantages which also includes skills and the abilities that employees are expected to have or develop. Employee competencies, therefore, remain as core competencies areas needed to be properly evaluated for a firm to be competitively relevant in the market. Asides the above definitions, an inclusive explanation has also been offered by the various competency models. Competency model refers to the list of competencies that are obtained from the observable satisfactory or exceptional employee performance of a particular job, which can be used to categorised competencies for common use [1]. The two types of competency models to be analysed for better understanding of individual competencies in an organisation include: the iceberg competency model and the general competency model of Boyaltzis.

The iceberg competency model presents human structure of competency in form of iceberg. This model divides competence into two parts: the upside water surface competence and the below water surface competence. The components of the upside water surface competence include skills and knowledge (know-how). These components can be observed and measured and they are instrumental for the performance of job in an organisation. The below water surface components of the iceberg competency model include value, self-image, character/personality, self-force/social motivation and others. These components are the hidden, and, the most neglected competencies possess by individuals in an organisation. These components below the water surface of the iceberg model are the distinctive characteristics of individuals or employees within the organisations that will lead to superior performance. The iceberg model remains a veritable context for understanding individual competencies within the organisations

The other model necessary for understanding the concept of competence is the model put forward by Boyaltzis in 1982. According to Boyaltizis, there is a competence that can make managers to obtain achievement of some behaviour. In his investigation of 20 organisations and 20,000 managers, Boyaltziz came out with a general competence model with 21 competence features. The Boyaltzis's 21 competence features as cited in [30] include: correct self-appraisement, generalities, notice close relation, emphasis result, developing other person, judge ability, effective location, logicality thought problem, group team management, memory, objectivity, attitude positive, initiative, selfconfident, self-control, professional knowledge, sense of responsibility, willpower with meet ability, express ability orally, good at use the strength of the masses, and good at utilised can use resources.

The models present a clear view that individual competencies remain the aspect of the core competencies needed for obtaining superior performance in an organisation. Through these models, the importance of people as a unique resource to obtain competitive advantage has been emphasised. People are the ultimate creator of quality products and services and not technology, work processes or formal quality procedures. It is therefore important for the management of an organisation to invest in the development of the competencies of employees for the purpose of obtaining competitive advantages.

\subsection{Competence-Enhancing Interventions and Performance}

Competence-enhancing interventions refer to the practices 
that are considered essential for developing and enhancing the competencies of employees for the efficient and effective performance of the jobs they are employed to do in an organisation. In the empirical studies in HRM literature, staffing and training and development practices have been identified as interventions for enhancing the employees' competencies towards attaining desired organisational outcomes [33-34], 14, 16).

Training and development are major practices that are designed to improve the skills and knowledge of employees so as to meet the demands of current jobs and also perform future assignments. In the study of Farouk, et al., (2016), the impact of Human resource management practices on performance was investigated in the banking sector in UAE, and training and development were identified as one of the practices for enhancing the competencies of employees working in the organisation [15]. The study concluded, through its findings, that training and development practices were positively related to performance. In the similar vein, the relationship between Human resource practices, business strategy and firm performance was investigated in steel industries in Taiwan and training and development practices were also found to be positively related to organisational performance [34]. These empirical studies and many other studies did not really specify training and development interventions or techniques for enhancing employees' competencies [12, 22, 35]. However, evidence from empirical study of the effectiveness of training and development on employees' performance and organisational competitiveness in some selected banks in Nigeria shows that training and development practices such as mentoring, coaching, job rotation, and apprentice are positively related to performance [33].

In a study on the development of sales force competencies and marketing performance, mentoring, project team staffing, coaching, and skill training were identified as competence development interventions for achieving marketing performance [14]. The study concluded that there was a significant relationship between these interventions and marketing performance of industrial and domestic product firms in Nigeria. In the similar vein, competence development practices such as job rotation programmes, mentoring and training were negatively related to turnover intention among highly skilled IT professional members of Canadian Information Processing Society [32]. In the study, training was separated from mentoring and job rotation programmes as the interventions for enhancing the competencies of IT professional members of Canadian Information processing Society. In another related study, coaching and task variety have been investigated as practices for enhancing the skills of employees in the organisation. Drawing from AMO framework, the study of Boselie (2010) concluded that coaching and task variety are part of skillsenhancing practices and were significantly related to organisational performance [20]. Job rotation has also been investigated as intervention for enhancing the skills and knowledge of workers in the organisation. Evidence from the studies on the effects of job rotation on organisational performance showed that job rotation remains a potent practice for enhancing employees' competencies and significantly related to organisational performance [36-37].

In other empirical studies on the practices for enhancing the workforce skills, staffing practices have been identified as interventions for getting competent employees on board in the organisation. In the empirical study of Obeidat, et al., (2016), staffing practices such as formal job analysis, recruitment, and selection as HRM interventions showed a significant relationship with organisational performance [22]. In the same vein, staffing processes such as rigorous selection and recruitment procedures are necessary practices that enable organisation to employ employees with the requisite skills, knowledge and abilities to function efficiently and effectively in the performance of their jobs in the organisation [38]. Staffing practices are consequential in HRM process because it helps to get competent employees on board who will respond quickly to other training and developmental practices put in place to enhance workers' competencies within the organisation.

\subsection{Organisational Performance}

There is no consensus conclusion among scholars in HRM literature as to the definition of performance in an organisation and this has led to the ambiguity in the clarification and definition of performance measures. Performance is seen as the driving force of every organisation. It can be best comprehended based on its measurement in an organisational setting. Performance refers to the aggregate measure of the outcome or output of an organisational activities and contribution towards its stakeholders [39]. It can also be seen as the measure of output of goods and services, which may be quantitative and qualitative, measure of time, and a measure of financial indicators [8]. Performance can also be measured in terms of outcomes. Performance can be measured in terms of outcomes such as organisational, financial, and market based outcomes [2]. Organisational outcomes can be measured in terms of productivity, quality and efficiency, financial outcomes can be measured by indicators such as profit, sales and ROI, and the market based outcomes can be measured by indicator such as stock price [2].

In an attempt to find how performance is conceived, scholars and researchers have used several indicators as performance measures in many empirical studies. Adopting quasi-perceptual measure, performance evaluation is based on objective terms such as return on equity, sales growth, and profitability [22]. In the study of Mariappanadar and Kramar, (2014), performance is measured in terms of profitability and absenteeism in an organisation [40]. Performance can also be measured in an organisation in term of operational performance [34]. The operational performance has four main dimensions: product quality, production cost, product delivery, and production flexibility Organisational performance using multiple variables such as sales growth, profitability, goal achievement, and good services [41]. 
The various performance indicators in the majority of the studies in Human resource management were based on outcomes at the organisational levels. These are the types of outcomes classified as distal outcomes. The impact of HRM interventions on distal outcomes is made possible through more proximal outcomes [2]. These proximal outcomes are referred to as human resource related outcomes. In the review of literature on competence-enhancing interventions, the emphasis on proximal outcomes is lacking, and, therefore, there is need to find out how these interventions impact on distal outcomes through proximal outcomes.

\subsection{Issues Arising from the Empirical and Theoretical Discussion}

As noted in the earlier discussion in this study, the concept of competence has been erroneously construed as 'skill' by many people. In order to have a deeper understanding of what individual competence is, the competence iceberg model has been the context that forms the basis of this study. Drawing from this model, competency is not only limited to skill and knowledge but it encompasses other unseen attributes of people that will occasion superior performance. The unseen aspects that make up attributes that influence people behaviour towards achieving superior performance include value, trait, self-image, character/personality, selfforce/social motivation. The attributes which are considered hidden are largely the most neglected aspects of competencies possess by individuals or people working in the organisation.

A close scrutiny of the above reviewed literature shows that that an anecdotal part of what constitutes competency has been addressed by researchers and scholars. The reviewed literature shows that efforts were devoted to skills and knowledge enhancement on the part of people working in the organisation. The reviewed studies dwelt much on training and development and selection practices as interventions for enhancing the skills and knowledge of organisational workforce for achieving performance $[14 ; 18$; $33 ; 35 ; 38]$. These studies have not really captured the other aspects of competencies that can lead to superior performance. Therefore, studies should be mounted to identify various interventions necessary to enhance other aspects that make up individual competencies in the organisation. Efforts should be directed at investigating interventions for enhancing employees' motivation, personality, values, self-image, traits and other attributes that will influence or affect performance in an organisation.

Apart from the all-embracing interventions to capture employees' competencies, the unit of analysis as a basis of investigation should also be addressed. The reviewed studies investigated the practices for enhancing competencies at the macro level in the organisation. The effectiveness of these practices were analysed based on the views or opinions of people at the managerial levels in the organisation $[7 ; 14 ; 15$; $32 ; 41]$. In order to really comprehend what constitutes individuals competencies, investigation should be addressed to the micro level of the organisation. The people who are working in the organisation are the direct beneficiaries of these interventions or practices, therefore, it is pertinent to inquire from them how effective are these practices or interventions to the enhancement of their competencies. Asides, the micro level analysis will provide more light on whether organisations are having these practices or interventions notionally or in demoralised and dysfunctional conditions.

The theories reviewed in this study show that there is connectivity between the constructs of HRM practices and organisational performance. The theories provided a platform for researchers and scholars, most especially in the field of Human resource management, to understand how constructs can be modeled. In the empirical literature reviewed, there is lack of appropriate theories to model the constructs of competence-enhancing interventions and organisational performance. It is therefore important to mobilise relevant theories to underpin the understanding of interventions for enhancing competencies and its connection to organisational performance.

\section{The Call for Theoretical Framework}

The reviewed theoretical, conceptual and empirical studies have clearly brought out what makes up individual or aggregate employee competencies in the organisations. There is therefore the need to enhance these competencies through the necessary HRM interventions so as attain superior performance. However, the selection of HRM interventions remains a controversial issue in the Human resource literature. Out of the three perspectives to HRM practicesuniversalistic, configurational, and contingency, none of them has been identified as the best practices but emphasis has accorded the use of complementary HRM interventions that work in concert and reinforce common effects in individuals for achieving performance. Furthermore, the plea on the use of theory and theories in Human resource management has been identified as a better way to comprehend which HRM practices will impact on organisational performance [8].

Based on the need for theories on HRM interventions, performance, and the linkage between them, this study will model the constructs of competence-enhancing interventions and performance, and the linkage between them using existing relevant theories. This study proceeds to suggest a conceptual model or framework for guiding future research studies in the field of Human resource management.

\subsection{The Proposed Conceptual Framework}

In line with the argument preceding this section, this study proposes the following conceptual framework. The proposed framework consists of four constructs: independent, dependent, intervening, and moderating constructs. The independent construct is a composite variable that is operataionalised into three latent variables using AMO theory: ability, motivation, and opportunity-enhancing interventions. The dependent variable is operationalized as 
organisational performance which is to be measured as flexibility, efficiency, and operational quality. The relationship between the independent and dependent constructs will be mediated by employee commitment, and the strength of the independent variable on the dependent variable will be moderated by the construct of organisational justice. The proposed framework will provide understanding for future empirical research on how competence-enhancing interventions will create discretionary efforts on the part of individuals at workplace and how the efforts will lead to performance outcomes in the field of Human resource management. The study then discusses the linkages.

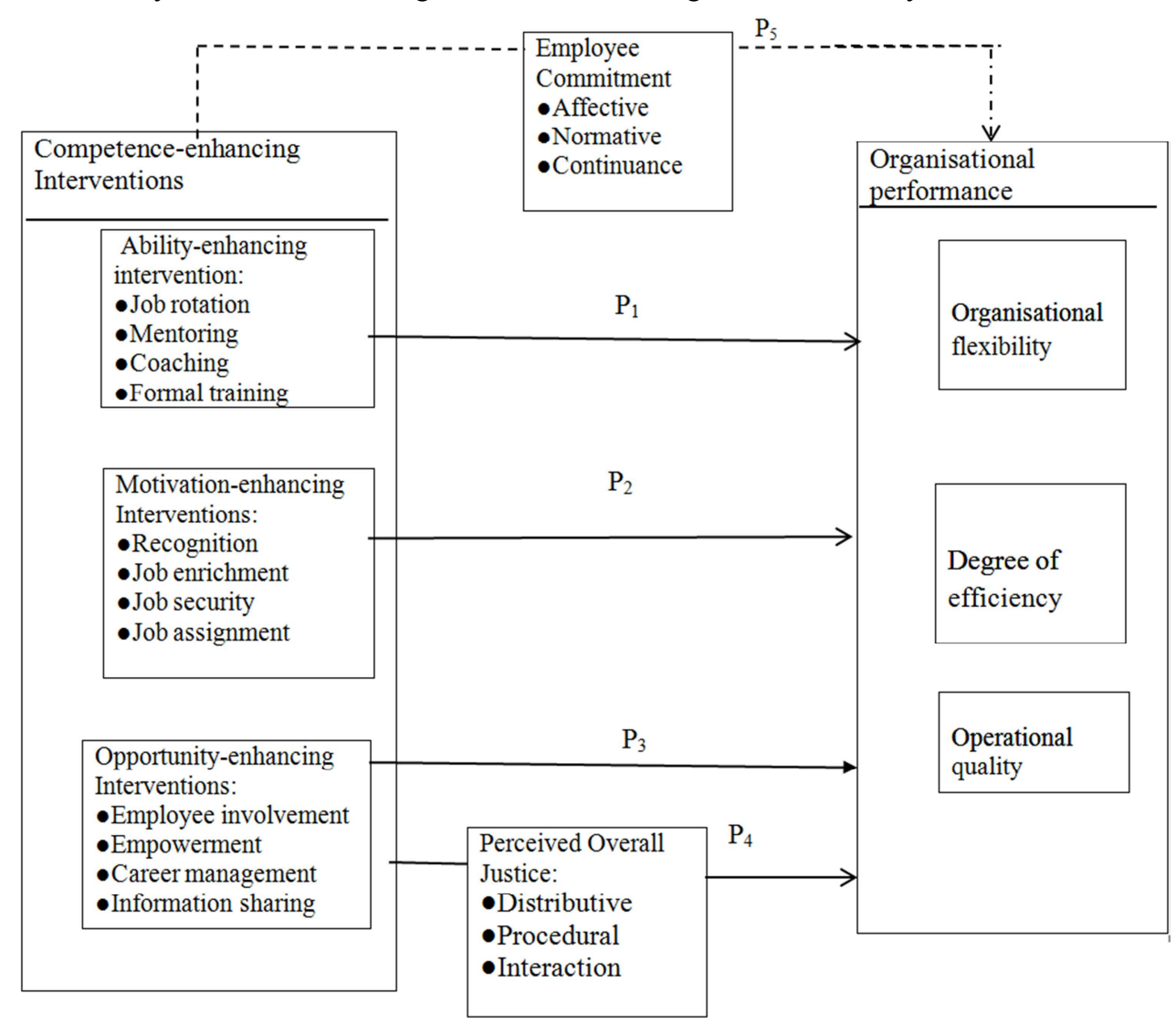

Figure 1. A theoretical model linking the constructs of competence-enhancing interventions and organisational performance.

\subsection{Competence-Enhancing Interventions}

As earlier discussed in the reviewed literature, employee competence entails not only skill and knowledge but also attributes that are essential for the performance of jobs or tasks people are employed to do in an organisation [5]. These attributes that make up employees' competencies include trait, values, character/personality, motivation, self- image, and they are considered significant for achieving superior performance. The composite construct of competenceenhancing interventions in the proposed framework is operationalized into three dimensional ways using AMO theory. The first dimension caters for the interventions that are considered as ability enhancing, the second dimension covers interventions for enhancing motivation of people working in the organisation, and the third dimension embraces interventions that enhance opportunity for people to participate in the activities or affairs of the organisation. The three dimensions are operationalized as follows:

Ability-enhancing Interventions: The ability-enhancing interventions as operationalised in the model entail the practices that are considered salient in improving the skills and knowledge of employees at workplace towards attaining organisational performance. Drawing from Resource-Based View that sustainable competitive advantage can be achieved by developing resources that are valuable, rare, inimitable and non-substitutable; then, organisation can invest in interventions for building the skills and knowledge of its employees so as to obtain sustainable competitive advantage. As argued in the literature, sustainable competitive advantage remains a significant factor for achieving success in today's global competitive environment. Therefore, human resource remains as key to the attainment the success that an organisation desires. In the light of this explanation, this study therefore proposes that:

Proposition 1: The ability-enhancing interventions will be having a direct relationship with organisational performance

Motivation-enhancing Interventions: It is important to enhance the ability of employees by investing in their skills and knowledge but without adequate motivation the enhancement exercise remains an effort in futility. Motivation-enhancing interventions are practices that can drive employees to adequately make efficient and effective use of the acquired skills and knowledge. The construct is operationalized using AMO 
theory with the necessary practices or interventions that can motivate or drive employees to assume discretionary behaviours in an organisation. Drawing from Social Exchange theory, if employees perceived that their organisations are interested in investing in the necessary interventions to enhance their competencies, they may likely to reciprocate by exhibiting positive behaviour which in turn will lead to performance in the organisation. Based on this explanation, the study proposes that:

Proposition 2. Motivation-enhancing interventions are directly associated with organisational performance

Opportunity-enhancing Interventions: This construct is operationalized as interventions that give room for employees to participate in the decisions that affect them and the entire organisation. If employees are involved in the decision-making exercises that affect them in the organisation, they may see themselves as significant to the organisation and this may boost their self-images, personalities, motivation, characters in a positive way which, in turn, may lead to organisational performance. Drawing from Affective Events theory, opportunity-enhancing interventions may be seen as events that can create positive affective mood among employees which in turn lead to organisational effectiveness. In view of this explanation, the study therefore proposes:

Proposition 3. There is a direct relationship between opportunity-enhancing interventions and organisational performance

\subsection{Competence-Enhancing Intervention, Perceived Overall Justice, and Performance}

The reviewed literature shows that a relationship exists between some set of HRM interventions and performance in the organisation. But effort has not been channelled to find out whether these set of HRM interventions are only available in the figment of imagination of several organisations. There is need to find out from the point of employees whether performance in the organisation is contingent on the overall fairness perception of competenceenhancing interventions. Drawing from the law of reciprocity from Social Exchange theory, if employees perceived fairness in terms of interventions to enhance their competencies, they may likely see it as a gesture to give back to the organisation in terms of efficient and effective performance. Based on this explanation, the study proposes that:

Proposition 4. Perceived overall justice moderates the effects of competence-enhancing interventions on organisational performance

\subsection{Competence-Enhancing Interventions, Employee Commitment and Organisational Performance}

As indicated in the proposed framework, competenceenhancing interventions comprise some set of HRM practices for developing human resource as an asset that organisation desires to achieve its predetermined goal. It has been argued in HRM literature that these set of practices do not only directly impact on performance but also in indirect way [42]. One of the indirect ways through which these practices influence performance is through human resource outcomes. Human resource outcomes are proximal outcomes through which distal outcomes (performance) are impacted by HRM practices [2]. In the line of this argument and drawing from AMO theory that discretionary behaviour results from ability, motivation and opportunity to participate by employees, the study proposes that:

Proposition 5. Employee commitment mediates the effects of competence-enhancing interventions on organisational performance.

\section{Conclusion and Direction for Future Research}

This study has discussed the constructs that make up the interventions for enhancing individual competencies and organisational performance. The theoretical and empirical literature has also beamed light on how the constructs of competence-enhancing interventions and organisational performance are modelled. Drawing conclusion from theoretical and empirical literature, a conceptual framework that predicts the linkages among the constructs of the study at the micro level of an organisational context is discussed. The conclusion of this study however faces three limitations. Firstly, the study is relied on few theories for modelling its constructs. Secondly, the set of interventions selected for enhancing employee competencies cannot be termed as best, bundle or configuration of set of practices. Thirdly, the conclusions constitute theoretical propositions that are yet to be empirically tested and validated using data from a field survey. In view of these limitations, the theoretical propositions advanced in this study can be empirically investigated and validated, using data from any form of organisations, in future studies.

\section{References}

[1] Özçelik, G., \& Ferman, M. (2006). Competency approach to human resources management: Outcomes and contributions in a Turkish cultural context. Human Resource Development Review, 5(1), 72-91.

[2] Savaneviciene, A., \& Stankeviciute, Z. (2012). Human resource management and performance: From practices towards sustainable competitive advantage. In GlobalizationEducation and Management Agendas. InTech.

[3] Ulrich, D., \& Lake, D. G. (1990). Organizational capability: Competing from the inside out. John Wiley \& Sons.

[4] Bontis, N., Dragonetti, N. C., Jacobsen, K., \& Roos, G. (1999). The knowledge toolbox: A review of the tools available to measure and manage intangible resources. European management journal, 17(4), 391-402.

[5] Boyatzis, C. J. (2000). The artistic evolution of Mommy: A longitudinal case study of symbolic and social processes. New directions for child and adolescent development, 2000(90), 5-29. 
[6] Adomi, E. E. (2006). Job rotation in Nigerian university libraries. Library Review, 55(1), 66-74.

[7] Zaim, H., Yaşar, M. F., \& Ünal, Ö. F. (2013). Analyzing The Effect of Individual Competencies of Performance: A Field Study in Services Industries in Turkey. Journal of Global Strategic Management, 14(2).

[8] Guest, D. E. (1997). Human resource management and performance: a review and research agenda. International journal of human resource management, 8(3), 263-276.

[9] Boxall, P., \& Macky, K. (2009). Research and theory on highperformance work systems: progressing the high-involvement stream. Human Resource Management Journal, 19(1), 3-23.

[10] Karatepe, O. M. (2013). High-performance work practices, work social support and their effects on job embeddedness and turnover intentions. International Journal of Contemporary Hospitality Management, 25(6), 903-921.

[11] Kelliner, A., Townsend, K., Wilkinson, A., Greenfield, A., \& Lawrence, S. (2016). The message and the messenger: Identifying and communicating a high performance "HRM philosophy". Personnel Review, 45(6), 1240-1258.

[12] Muduli, A. (2015). High performance work system, HRD climate and organisational performance: an empirical study. European journal of Training and development, 39(3), 239-257.

[13] Smith, A., Oczkowski, E., Noble, C., \& Macklin, R. (2003). New management practices and enterprise training in Australia. International Journal of Manpower, 24(1), 31-47.

[14] Asiegbu, F. I., Awa, H. O., Akpotu, C., \& Ogbonna, U. B. (2011). Sales force competence development and marketing performance of industrial and domestic products firms in Nigeria. Far East J Psychol. Bus, 2(3), 43-59.

[15] Farouk, S., Abu Elanain, H. M., Obeidat, S. M., \& Al-Nahyan, M. (2016). HRM practices and organizational performance in the UAE banking sector: The mediating role of organizational innovation. International Journal of Productivity and Performance Management, 65(6), 773-791.

[16] Yazdanfar, D., Abbasian, S., \& Hellgren, C. (2014). Competence development and performance among Swedish micro firms. European Journal of Training and Development, 38(3), 162-179.

[17] Barney, J. (1991). Firm resources and sustained competitive advantage. Journal of management, 17(1), 99-120.

[18] Appelbaum, E., Bailey, T., \& Berg, P. A. Kalleberg (2000). Manufacturing advantage: Why high-performance work systems pay off.

[19] Purcell, J., Kinnie, K., Hutchinson, S., Rayton, B., \& Swart, J. (2003). People and Performance: How people management impacts on organizational performance. London: CIPD.

[20] Boselie, P. (2010). High performance work practices in the health care sector: a Dutch case study. International Journal of Manpower, 31(1), 42-58.

[21] Denton, K. (2006). High performance work systems: the sum really is greater than its parts. Measuring Business Excellence, 10(4), 4-7.

[22] Obeidat, S. M., Mitchell, R., \& Bray, M. (2016). The link between high performance work practices and organizational performance: Empirically validating the conceptualization of HPWP according to the AMO model. Employee Relations, 38(4), 578-595.

[23] Pichler, S., Varma, A., Yu, A., Beenen, G., \& Davoudpour, S. (2014). High performance work systems, cultures and gender demography. Employee Relations, 36(6), 693-707.

[24] Mostafa, A. M. S. (2017). High-performance HR practices, positive affect and employee outcomes. Journal of Managerial Psychology, 32(2), 163-176.

[25] Fisher, C. D. (2003). Why do lay people believe that satisfaction and performance are correlated? Possible sources of a commonsense theory. Journal of Organizational behavior, 24(6), 753-777.

[26] Wegge, J., Dick, R. V., Fisher, G. K., West, M. A., \& Dawson, J. F. (2006). A test of basic assumptions of affective events theory (AET) in call centre work. British Journal of Management, 17(3), 237-254.

[27] Jackson, S. E., \& Schuler, R. S. (1995). Understanding human resource management in the context of organizations and their environments. Annual review of psychology, 46(1), 237-264.

[28] Delery, J. E., \& Doty, D. H. (1996). Modes of theorizing in strategic human resource management: Tests of universalistic, contingency, and configurational performance predictions. Academy of management Journal, 39(4), 802-835.

[29] Chang, W. J., \& Chun Huang, T. (2005). Relationship between strategic human resource management and firm performance: A contingency perspective. International journal of manpower, 26(5), 434-449.

[30] Liu, X., Ruan, D., \& Xu, Y. (2005). A study of enterprise human resource competence appraisement. Journal of enterprise information management, 18(3), 289-315.

[31] McClelland, D. C. (1973). Testing for competence rather than for "intelligence". American psychologist, 28(1), 1.

[32] Paré, G., \& Tremblay, M. (2007). The influence of highinvolvement human resources practices, procedural justice, organizational commitment, and citizenship behaviors on information technology professionals' turnover intentions. Group \& Organization Management, 32(3), 326-357.

[33] Falola, H. O., Osibanjo, A. O., \& Ojo, S. I. (2014). Effectiveness of Training and Development on Employees'performance and Organisation Competitiveness in the Nigerian Banking Industry. Bulletin of the Transilvania University of Brasov. Economic Sciences. Series V, 7(1), 161.

[34] Lee, F. H., Lee, T. Z., \& Wu, W. Y. (2010). The relationship between human resource management practices, business strategy and firm performance: evidence from steel industry in Taiwan. The International journal of human resource management, 21(9), 1351-1372.

[35] Bourne, M., Pavlov, A., Franco-Santos, M., Lucianetti, L., \& Mura, M. (2013). Generating organisational performance: The contributing effects of performance measurement and human resource management practices. International journal of operations \& production management, 33(11/12), 1599-1622.

[36] Baro, E. E. (2012). Job rotation program evaluation: the Niger Delta University library. In Aslib Proceedings (Vol. 64, No. 4, pp. 388-404). Emerald Group Publishing Limited.

[37] Adomi, E. E. (2006). Job rotation in Nigeria university libraries. Library Review, 55(1), 66-74 
[38] Karatepe, O. M., \& Olugbade, O. A. (2016). The mediating role of work engagement in the relationship between highperformance work practices and job outcomes of employees in Nigeria. International Journal of Contemporary Hospitality Management, 28(10), 2350-2371

[39] Wong, C. Y., Boon-Itt, S., \& Wong, C. W. (2011). The contingency effects of environmental uncertainty on the relationship between supply chain integration and operational performance. Journal of Operations management, 29(6), 604615.

[40] Mariappanadar, S., \& Kramar, R. (2014). Sustainable HRM: The synthesis effect of high performance work systems on organisational performance and employee harm. Asia-Pacific Journal of Business Administration, 6(3), 206-224.

[41] Chand, M., \& Katou, A. A. (2007). The impact of HRM practices on organisational performance in the Indian hotel industry. Employee Relations, 29(6), 576-594.

[42] Youndt, M. A. (2000, August). Human resource considerations and value creation: the mediating role of intellectual capital. In Paper delivered at National Conference of US Academy of Management. 